\title{
OS PRINCÍPIOS DA FILOSOFIA POLÍTICA DE ROUSSEAU: VONTADE GERAL E SENTIMENTO MORAL NO DEBATE SOBRE A UNIVERSALIDADE DOS DIREITOS HUMANOS
}

\author{
THE PRINCIPLES OF ROUSSEAU'S POLITICAL PHILOSOPHY: THE GENERAL WILL \\ AND THE MORAL FEELING IN THE DEBATE ON THE UNIVERSALITY OF THE HUMAN \\ RIGHTS
}

\author{
NATALIA MARUYAMA \\ (PUC / Campinas)
}

\begin{abstract}
RESUMO
A idéia do contrato social na obra de Rousseau exige a elaboração de uma teoria da subjetividade. A concepção da consciência moral, assim como as idéias gerais de ordem, bem e justiça, podem ser consideradas como partes da estratégia do autor visando formular uma nova racionalidade para o direito político, fundada no princípio da vontade geral. Seus princípios não são princípios a priori da reta razão, como aqueles sobre os quais se fundavam as teorias do direito natural, nem tampouco estão desvinculados dos sentimentos morais. Com a teoria da vontade geral, Rousseau incorpora à filosofia política e jurídica a idéia de que a razão, a linguagem e as paixões se articulam, propondo uma nova teoria contratual que pretende dar conta ao mesmo tempo da diversidade dos povos e dos princípios universais. A idéia geral dos direitos do homem resulta, então, das considerações acerca de sua historicidade, atreladas à investigação sobre a linguagem. Esse percurso revela-nos as influências da Filosofia das Luzes nas concepções contemporâneas dos direitos humanos, seu estudo trazendo contribuições para o debate sobre a universalidade desses direitos.

Palavras-chave: Contrato social, direitos do homem, razão, sentimento moral, subjetividade, vontade geral.
\end{abstract}

\begin{abstract}
The idea of social contract in Rousseau's work requires the development of a theory of subjectivity. The conception of conscience as well as the general ideas of order, good and justice can be considered as part of the author's strategy aiming at to formulate a new rationality for the political right, founded on the principle of the general will. His principles are not an a priori principle of the right reason, such as those on which were founded on the theories of natural law, nor are released from the moral sentiments. With the theory of general will, Rousseau incorporates to the political and legal philosophy the idea that reason, the language and passions fit together, proposing a new theory of contract which is meant to capture both the diversity of peoples and universal principles. The general idea of human rights results, then, of the consideration concerning its history, tied to a language investigation. This passage reveals the influences of the Philosophy of the Enlightenment in the contemporary conceptions of human rights, bringing his study contributions to the debate on the universality of these rights. Keywords: social contract, human rights, reason, moral feeling, subjectivity, general will.
\end{abstract}

Na tradição de comentários da Declaração dos direitos do homem e do cidadão de 1789, vale a pena ressaltar a discussão acerca da gênese do conceito de direitos humanos. Essa discussão apresenta-se em duas perspectivas, conforme priorize a investigação mais teórica acerca do estatuto dos direitos do homem - se são naturais, divinos ou se são idéias da razão, portanto, nesse último 
caso, amparados nas filosofias do sujeito - ou, em outra via, uma pesquisa acadêmica, de cunho mais historiográfico, dirigindo-se ao estudo das fontes teóricas de tal conceito ${ }^{1}$.

Com base nessa discussão, que é, portanto, ao mesmo tempo filosófica e historiográfica, chamamos atenção para alguns aspectos da obra de J.-J. Rousseau que nos permitem justificar uma posição em defesa da universalidade dos direitos humanos. Embora não haja nessa obra uma concepção acabada acerca dos chamados "direitos do homem", sua influência na Declaração de 1789 é inquestionável. Propomos examinar a problemática da universalidade dos direitos humanos à luz de um estudo da obra de Rousseau que contemple, desde seus primeiros princípios acerca da linguagem e das paixões, no Discurso sobre a origem da desigualdade entre os homens, até suas reflexões sobre o direito implicadas na teoria da vontade geral, tal como é formulada no Contrato social, e a metafísica esboçada na Profissão de fé do vigário saboiano, peça mestra da filosofia moral de Rousseau, que figura no Livro IV de sua obra Emílio ou da Educação.

A primeira questão que se coloca concerne ao vínculo entre os chamados direitos do homem e a concepção dos direitos naturais, afinal, a Declaração de 1789 se apresenta como exposição dos direitos naturais, inalienáveis e sagrados do homem. Para Rousseau, os direitos naturais ou, ainda, em outras palavras, os "direitos naturais raciocinados", não são conteúdos mentais a priori; eles fazem parte do conjunto de idéias que podemos obter por uma razão que é instruída (ou, se preferirmos, que é guiada) pelos sentimentos morais. A idéia dos direitos naturais, assim como a idéia de humanidade, para Rousseau, são formadas a partir de generalizações e não pressupõem os sentimentos morais tomados numa perspectiva empírica ${ }^{2}$. Tais sentimentos, aliás, seriam, aos olhos do autor, muito vagos para poderem servir de base ou sustentação dos princípios do direito positivo ou da idéia dos direitos do homem. Recorrendo aos sentimentos morais como base de uma idéia acerca do direito natural, fazemos uma referência a princípios presentes no espírito humano, mesmo que em estado de potencialidade, como uma possibilidade, portanto, e não como uma emoção agindo no espírito ou na alma. Toda a metafísica do vigário saboiano, quando Rousseau formula sua teoria dos sentimentos morais, aponta-nos para esse aspecto da consciência humana. Uma coisa é dizer que sentimentos (ou emoções) estão sempre na mente, atuando em quaisquer circunstâncias. Outra é dizer que princípios ou sentimentos inatos aguardam objetos aos quais possam se aplicar quando lhes são apresentados adequadamente. Nosso autor não aceita a primeira posição e, ao defender o inatismo dos sentimentos morais, explora a segunda.

Seja como for, quando nos dirigimos à Declaração de 1789, notamos que a idéia dos direitos do homem e do cidadão, tal como fora aí formulada, supõe uma concepção concernente aos direitos naturais, que são apresentados como direitos inalienáveis e sagrados do homem. O texto supõe também um princípio que podemos caracterizar como um princípio de igualdade de direitos. Tal igualdade se estabelece, porém, pelo nascimento, como nos revela o Artigo 1: "Os homens nascem e permanecem livres e iguais em direitos". Há aqui dois aspectos que vale ressaltar: o da sacralidade ou da naturalidade, assim como o de sua inerência, enquanto direito igual a todos, àquele que passa 
pelo nascimento. Em ambos os casos, embora sob perspectivas diversas, lidamos com a questão do originário.

Além desses dois aspectos de tal concepção dos direitos do homem, encontramos na Declaração a premente discussão sobre a liberdade e a lei. Esta última figura no Artigo 6 como expressão da vontade geral. Ora, importa-nos aqui compreender melhor a referência à vontade geral, pois esta nos traz elementos preponderantes para o debate sobre a universalidade dos direitos humanos. Nas passagens iniciais do texto, tratava-se de declarar como princípio inquestionável aquilo que é sagrado ou que é caracterizado como natural e inalienável ou, ainda, tratava-se de afirmar os direitos como algo inerente a todos aqueles que nascem. Neste ponto, temos que fazer alguma concessão ao fato de que tais aspectos são apresentados de modo afirmativo e categórico. O mesmo tom não decorre espontaneamente de nossos discursos, quando passamos desse plano aparentemente restrito ao campo biológico - já que se trata do nascimento, portanto, de uma qualidade de ser vivo - para as formulações dos direitos do homem e do cidadão manifestas nos Artigos da Declaração que incidem sobre as considerações acerca da lei e da liberdade. Neste último caso, o texto coloca também, e mais diretamente, a necessidade de se pensar a importância dos mecanismos políticos, econômicos e sociais como elementos que fornecem a condição de aplicabilidade da idéia dos direitos humanos.

Tais considerações não implicam, contudo, que sejam tomados apenas, como pressupostos fundamentais, os aspectos convencionais dos direitos, o que seria até mesmo contraditório do ponto de vista da filosofia do Dixhuitième. Os direitos do homem são, bem entendido, originários. Isso faz parte de seu estatuto. Eles são dádivas cedidas ao homem pela natureza ou por Deus, não podendo, portanto, ser caracterizados propriamente como simples direitos inventados pela mente humana como se, com isso, se pretendesse lhes atribuir um aspecto ilusório ou fantasioso. É assim que Rousseau apresentava a vontade livre e a liberdade, sejam estas pensadas no sentido de uma qualidade natural, como vemos no Discurso sobre a desigualdade, com a caracterização da independência do homem no estado puro de natureza, ou no sentido metafísico, cuja teoria é formulada no Emílio e pressuposta no Contrato social. Nossa problemática concerne, ao mesmo tempo, à origem e à universalidade dos direitos humanos. Dizemos "ao mesmo tempo" porque nem sempre a questão da origem se confunde com a da universalidade. Com efeito, se fosse possível aqui demonstrar que os direitos do homem são efetivamente originários, seja como dons da natureza ou como dádivas divinas, seja como qualidades inerentes ao homem enquanto tal ou como elementos essenciais que constituem a própria dignidade humana, a questão de sua universalidade apareceria, no que diz respeito aos seus fundamentos teóricos, como uma conseqüência imediata.

Mas essa questão não pode ser resolvida de modo tão simples. Nosso problema consiste precisamente em investigar que tipo de universalidade é esta, que podemos conferir aos direitos humanos mesmo quando negamos a necessidade de fundamentação de tal conceito. Pensamos aqui, 
mais particularmente, na posição de N. Bobbio acerca dos fundamentos dos direitos do homem. Em seu livro A Era dos direitos, este autor nos propõe três questões ${ }^{3}$ : 1) Qual o sentido do problema acerca do fundamento absoluto dos direitos do homem? 2) É possível um fundamento absoluto dos direitos do homem? 3) É desejável um fundamento absoluto para os direitos do homem?

Em relação à primeira questão, a busca de reconhecimento justificaria, segundo Bobbio, a busca pelo fundamento. Esse comentário condiz literalmente com o que é notável na Declaração universal dos direitos humanos, de 1948. Lembremos que no Preâmbulo desse texto o que figura como fundamento é o reconhecimento dos direitos humanos, o reconhecimento da dignidade inerente a todos os membros da família humana e de seus direitos iguais e inalienáveis. É o reconhecimento universal dos direitos humanos que aparece como fundamento da liberdade, e não o contrário. Nesse sentido, é justificável a busca pelo fundamento dos direitos humanos. Tal atitude faz parte de uma luta pelo reconhecimento desses direitos. Todavia, para Bobbio, a resposta às duas últimas questões se dá pela via negativa: não é possível nem desejável encontrarmos um fundamento absoluto para os direitos do homem. Aqui reside o cerne de nosso problema concernente à universalidade dos direitos do homem.

Quanto à segunda questão - É possível um fundamento absoluto dos direitos do homem? - as dificuldades que o autor aponta para sustentar sua posição de negação da possibilidade de se encontrar um fundamento absoluto para o conceito dos direitos do homem são as seguintes: a) A expressão direitos do homem é muito vaga, suas definições são tautológicas. Esses direitos são considerados, comumente, como condições para a realização de valores últimos e, por isso, tais valores são empregados para fundamentar os direitos do homem. Todavia, eles mesmos, os valores últimos, carecem de fundamentação ou de justificação. É preciso simplesmente assumi-los como fundamentos últimos; b) Os direitos do homem constituem uma classe variável ao longo da história. O que se considera como direito fundamental numa época não é o que se considerará como fundamental em outra época. Trata-se aqui, com efeito, de um argumento voltado à relatividade dos direitos, decorrente de sua variabilidade histórica; c) A classe dos direitos do homem é heterogênea; direitos de primeira geração têm estatutos distintos dos direitos de segunda geração, não podendo ter todos os direitos humanos, portanto, um único fundamento; d) Há contradições entre os direitos na Declaração. O autor nos chama atenção para o fato de que certos direitos implicam as liberdades individuais, no sentido negativo, isto é, liberdades que se efetivam na ausência de uma ação que as contrarie. Outros direitos envolvem, para serem realizados, poderes, isto é, ações positivas, obrigações positivas. Assim, portanto, como no argumento anterior, Bobbio enfatiza aqui a heterogeneidade envolvida nas idéias dos direitos do homem, conforme estejam referidas aos direitos de primeira geração (direitos fundados nas liberdades individuais), aos de segunda geração (direitos econômicos e sociais, no âmbito do trabalho, da saúde e da educação) ou aos direitos de terceira geração (direitos de solidariedade, atrelados às questões do meio ambiente, por exemplo).

No que concerne à terceira questão - É desejável um fundamento absoluto para os direitos 
do homem? - caberia investigar se essa busca, ainda que seja possível existir tal fundamento, pode obter resultados, isto é, se buscar um fundamento absoluto para os direitos do homem torna possível que se consiga, também, o reconhecimento e a realização desses direitos. Em outras palavras, para o autor, seria preciso direcionar a busca pelo fundamento dos direitos humanos a um imperativo acerca de sua realização e eficácia, imperativo que, como notamos, é incorporada à Declaração de 1948 como sendo o próprio fundamento da liberdade.

Essa crítica à investigação filosófica concernente ao estatuto dos direitos humanos tem relevância. Evidentemente, entre a Declaração de 1789 e a Declaração de 1948, assistimos a um deslocamento na discussão sobre os fundamentos dos direitos humanos. Se, no período revolucionário do XVIII francês, os direitos do homem - que, vale destacar, são considerados também como direitos do cidadão - aparecem sob a auréola imaculada do sagrado (direitos naturais, inalienáveis e sagrados do homem), no período que se segue à Segunda Guerra Mundial a ênfase não recai sobre a questão da origem dos direitos humanos, mas sobre a necessidade, universal, do respeito e do reconhecimento de tais direitos por todos os povos. A universalidade dos direitos humanos não decorre, pois, de sua origem, mas de seu reconhecimento, seu respeito e sua observância.

É importante ressaltarmos que a investigação acerca dos fundamentos e da universalidade dos direitos do homem tem ainda um percurso a cumprir antes que possa ser considerada obsoleta ou ineficaz. Temos um exemplo concreto, a do debate em torno dos direitos originários envolvidos nas reservas indígenas brasileiras. Não obstante a distância entre as duas Declarações, é mister relançarmos um olhar para esse período da história, o XVIII francês, cujas contribuições são determinantes para a história da filosofia jurídica. Mantemo-nos, assim, atentos à exigência de eficácia implicada nos estudos do conceito dos direitos do homem, exigência premente no contexto da diversidade dos povos e das culturas, mas que não prescinde da investigação filosófica. Nesse sentido, revisitar a filosofia moderna permite-nos compreender aspectos determinantes para a formulação adequada da problemática atual dos direitos do homem, a saber, aquela que envolve a ordem da inteligibilidade, na medida em que essa inteligibilidade é a condição que torna possível (ou efetivo) o reconhecimento da idéia dos direitos do homem.

\section{A vontade geral e o problema da origem dos direitos humanos}

Como poderíamos falar em reconhecimento e respeito aos direitos humanos sem refletirmos também acerca de sua importância, seu estatuto e, por conseqüência, sua origem? Quando, na modernidade, buscava-se explicar a origem das idéias e dos valores morais, assim como a dos princípios jurídicos e políticos, a intenção não era a de solapar os alicerces desses princípios, mas, ao contrário, a de fornecer parâmetros seguros para um exame adequado e uma melhor caracterização da moralidade e dos direitos considerados mais fundamentais. Assim, a questão de saber se os 
direitos do homem eram ou não direitos naturais, originários, inerentes à própria natureza humana ganhava tal relevância que não seria possível defendermos um direito sem antes atentarmos para a discussão acerca do estatuto de tal direito.

Toda a teoria contratual foi elaborada tendo como um de seus propósitos servir para a fundamentação dos direitos políticos e civis. Como se dá a relação entre a tese contratual e a idéia de que existem direitos do homem que lhe são essenciais e inalienáveis? Que limitação tal idéia traria para o poder político soberano? A quem, afinal, cabe decidir sobre o que é da alçada dos direitos do homem? No que diz respeito a essas questões, a teoria contratual tal como foi elaborada por Rousseau é uma demonstração acerca da importância de se considerar, antes, o sujeito do pacto político. $\mathrm{Na}$ perspectiva em que o autor pensa os princípios do direito e da moral, não seria possível formular a problemática concernente à universalidade dos direitos do homem sem a elaboração prévia de uma concepção acerca do sujeito político, isto é, daquele que contrata, instaurando com tal ato o direito. A questão da origem dos direitos do homem, na perspectiva contratualista, é inseparável da questão da eficácia, da observância e do reconhecimento desses direitos.

Fica claro na obra Do Contrato social, de Rousseau, que são os princípios do direito político que dirigem a formulação das obrigações civis e políticas, a começar pelo princípio da vontade geral, base de toda a legislação. O sistema de punições e recompensas e toda a aparelhagem administrativa de modo geral, seja esta voltada especificamente ao setor jurídico ou, de modo mais amplo, à educação, à vida política ou à economia, dependem desse único princípio, a vontade geral, pois é a vontade geral que funda todas as leis e, mais do que isso, é a vontade geral que marca no ato de criação da comunidade política mediante o contrato social o nascimento do próprio direito. Não haveria direito propriamente dito se não houvesse uma relação de liberdade, igualdade e reciprocidade no sistema gerado pela tese contratual. É porque cada sujeito contratante se coloca doravante diante dos outros membros da comunidade política enquanto pessoa moral, dotada de razão e liberdade, responsável pelas decisões públicas, vinculada à vontade geral, que se torna possível a vida em comunidade baseada na idéia do direito. Nesse sentido, se a instituição das leis depende da instauração do plano do direito em geral, a política tem primazia, pois dela depende o direito.

Faz parte da história das interpretações da obra de Rousseau a indagação acerca das conseqüências práticas do princípio da vontade geral. Em estudos anteriores, defrontamo-nos com as interpretações que atribuem aspectos totalizantes à teoria da vontade geral ${ }^{4}$. Cabe-nos aqui retomar a discussão focando-nos no problema da homogeneização dos indivíduos pertencentes à comunidade ordenada segundo o princípio da vontade geral. Excesso de importância atribuída à comunidade política em detrimento das manifestações individuais, tal é a posição de alguns críticos de Rousseau ${ }^{5}$. É claro que esse problema de interpretação é bastante complicado para ser resolvido aqui. Entretanto, podemos notar que não é possível vincularmos, sem cairmos em contradições, a idéia dos direitos humanos a princípios que atentem contra as liberdades individuais. Nessa discussão de interpretação da teoria contratual de Rousseau, alguns defendem que o princípio da 
vontade geral teria a conseqüência de atentar contra o indivíduo, contra a personalidade individual, nos termos de G. Gurvitch ${ }^{6}$. Precisamos, todavia, dissipar algumas confusões acerca da concepção de vontade geral, já que essa concepção faz parte das estratégias de fundamentação dos direitos do homem. O que deve ser feito a partir da fixação de algumas considerações acerca da definição da vontade geral na obra de Rousseau.

Antes de tudo, é preciso recordar que a vontade geral não se confunde com a vontade de todos. Ela não pode ser na prática tampouco uma imposição da maioria. As decisões em praça pública são tomadas a partir da opinião da maioria, cabendo aos indivíduos restantes que com essas decisões não concordam renunciar nesse caso específico a se pretenderem portadores da voz da vontade geral. Entretanto, tal não implica que se defina a vontade geral como voz da maioria. Ela não pode ser voz da maioria pela mesma razão que não pode ser confundida com a vontade de todos. A vontade geral não é definida de modo simplista, em relação ao número de vozes, por exemplo. Ela se caracteriza, ainda, quanto ao seu objeto, isto é, aquilo que ela aponta, define ou designa, e também quanto ao seu destinatário.

O objeto da vontade geral é sempre e necessariamente geral, ao passo que a vontade de todos pode incidir sobre os casos particulares ${ }^{7}$. A vontade geral não pode separar indivíduos nem objetos particulares, ela não diz respeito diretamente a casos concretos, mas apenas às definições e princípios, mantendo-se, portanto, por si mesma na generalidade. A vontade geral é, antes de tudo, um princípio: sua aplicação pertence a outra alçada. Assim como parte do todo - é voz de cada membro contratante no ato de instauração da comunidade política - e tem como objeto a generalidade das regras e princípios, a vontade geral volta-se para o todo. Seu destinatário é o conjunto de membros da comunidade política, sem discriminação de credos, cores, gêneros, idades. A vontade geral parte do todo, versa sobre o todo e destina-se ao todo, devendo buscar sempre, pois, o que é do interesse geral, coletivo.

Ora, tais considerações parecem, antes, aproximar a teoria da vontade geral das ações praticadas em sistemas sociais totalitários do que deles afastá-la. Segundo alguns intérpretes do pensamento de Rousseau, não haveria aqui espaço para as aspirações individuais, as quais se abdica em nome da comunidade política. A política se caracterizaria, então, como destruição das aspirações individuais, em benefício da busca pelos interesses coletivos. A homogeneidade parece, então, reinar lá onde a vontade geral se realiza, concretizando-se num apanágio de regras e normas desencarnadas, sem substância, demasiado abstrata e formal.

De modo algum. É preciso notar que em Rousseau a vontade geral nunca se define simplesmente como conceito ou princípio abstrato. Ela nos permite tratar das leis e das normas, fornecendo-nos parâmetros para aproximarmos as leis e as normas dos verdadeiros e reais interesses da comunidade política. Esses parâmetros, todavia, não são derivados de uma concepção essencialista da natureza humana, como se pudéssemos a partir da vontade geral impor regras e definições com 
algum estatuto próximo ao dos valores eternos, absolutos e universais. A vontade geral não versa diretamente sobre conteúdos. Ela é voz dos membros da comunidade política e ao mesmo tempo diz respeito aos interesses dessa comunidade, sem que com isso possa de antemão fixar o que é do interesse geral. Não há na teoria contratual de Rousseau uma batalha travada entre o todo e suas partes, ou uma posição a favor da sociedade ou do Estado, contra os indivíduos, como queriam alguns de seus intérpretes. Ainda que dê parâmetros para as leis e tenha como objeto o que é do interesse coletivo, a vontade geral jamais se volta diretamente contra os indivíduos ou as aspirações individuais. Ela não se constitui como um conteúdo determinado de antemão e deduzido de alguma concepção essencialista da natureza humana. Esta é a novidade da concepção de vontade geral de Rousseau: ela não requer um fundamento absoluto.

A vontade geral é a soma das diferenças. Diferentemente do que se supunha, ela não suporta a homogeneidade, não é uma verdade matemática ${ }^{8}$. Princípio do direito e das leis, a vontade geral não versa sobre as particularidades e, entretanto, de algum modo diz respeito às diferenças, às contrariedades, à multiplicidade. Não existiriam leis ou direitos estabelecidos se não houvesse contendas, conflitos, disputas. A multiplicidade e a heterogeneidade, a pluralidade de opiniões e culturas, integram o mundo moderno e fazem parte da história da construção dos conceitos de poder político, sociedade civil, cidadania. Precisamos das leis e das normas jurídicas porque vivemos juntos, e vivemos juntos sendo, contudo, diferentes. Que sentido haveria, por exemplo, no título da obra de Claude Buffier, de 1726, "Tratado da sociedade civil e do meio de se tornar feliz contribuindo para a felicidade das pessoas com quem se vive”, se precisássemos supor a existência de concordância e homogeneidade acerca do que é a felicidade?

Vale ressaltar que a concepção de vontade geral sofre algumas alterações no interior da obra de Rousseau. No início, mais particularmente no período em que nosso autor está redigindo o Discurso sobre a desigualdade, a vontade geral recebe um estatuto político bastante pronunciado, relativizando-se no ritmo das convenções e tratados, variando de acordo com as nações e as épocas ${ }^{9}$. Pode-se crer que, nesse caso, a vontade geral é da ordem da convenção, elemento cultural, princípio dinâmico. Mas, a julgar pelo sentido final da expressão vontade geral, o que é da vontade geral do corpo político não é mero resultado dos acordos estabelecidos, simplesmente um dado cultural, um traço característico de um povo ou uma opção de caráter nacional, mas vincula-se também à humanidade. Na versão primitiva do Contrato social, Rousseau discute com Diderot que, no verbete Direito natural da Enciclopédia, havia colocado a vontade geral como princípio racional, a que se tem acesso no silêncio das paixões ${ }^{10}$.

A vontade geral pertence também à ordem da sentimentalidade, marcando na política o lugar da subjetividade. Ela não supõe que se calem as paixões, mas, ao contrário, resulta da experiência interior e aflora juntamente com os sentimentos mais sublimes. O pacto político, tal como é pensado por Rousseau, equivale também a um engajamento interior, acordo do indivíduo consigo mesmo - como membro do Soberano em relação aos particulares, e como membro do 
Estado em relação ao Soberano, conforme lemos no Capítulo 7 do Livro I do Contrato social. Assim, se adotamos esse ponto de vista, o do sujeito do contrato social, a vontade geral ressurge como uma idéia da razão, princípio jurídico e, de certo modo, abstrato e formal, mas que, todavia, supõe participação, compromisso e engajamento pessoal. Nesse sentido, a vontade geral atrela-se também aos sentimentos da consciência moral, ela corresponde ao que há de mais íntimo no indivíduo e que faz dele um sujeito político, um ser responsável diante da comunidade à qual pertence. É a vontade geral, pela via da consciência moral, que permite que haja um sentimento de pertencimento no indivíduo em relação a sua comunidade.

Desse modo, a vontade geral, uma idéia da razão, articula-se também em relação à teoria da consciência apresentada no Emílio ou da educação. Todo esse arcabouço, que retira a vontade geral do anonimato das abstrações próprias aos princípios jurídicos, traz para o pensamento político de Rousseau uma proposta salutar: a arte de governar. Se nosso autor está de acordo com seu tempo ao enfatizar os aspectos culturais e históricos dos princípios morais e jurídicos, ele mantém uma exigência compatível com as idéias atuais de reconhecimento e respeito em relação a certos padrões subjetivos. Não se trata, pois, simplesmente de relativizar os princípios éticos e jurídicos afirmando sua historicidade, mas de acalentar a idéia de que a política não se pensa sem esses princípios, assim como tais princípios não podem ser retirados da alçada da vida em comum, isto é, numa comunidade política. Nesse sentido, defender os direitos naturais ou os direitos do homem requer que busquemos também as bases políticas que possam fundamentar e ao mesmo tempo assegurar sua aplicação e eficácia.

Há, portanto, coesão entre plano ético, plano político e plano jurídico a partir da tríade sentimentos morais, contrato social e vontade geral. É claro que tal solução para a interpretação da obra de Rousseau não é por si mesmo suficiente para nos permitir resolver o problema da universalidade dos direitos humanos. Ao contrário, ao estabelecermos um vínculo entre o princípio da vontade geral e os sentimentos da consciência moral, atentamos para o caráter subjetivo do direito e da vida política e dificultamos, com isso, nossa tarefa. Ao se ouvir falar em subjetividade ou em sentimentos morais pensa-se, em geral, de modo mais imediato, na variabilidade das coisas humanas, já que tais palavras parecem evocar a diversidade de opiniões, gostos, crenças e costumes. Como poderíamos fundar aqui a universalidade dos direitos do homem?

\section{O sentimento moral, a linguagem e a universalidade do direito}

A teoria da consciência moral, tal como fora exposta no Emílio de Rousseau, investiga as transformações no âmbito das paixões. Na Primeira Parte do Discurso sobre a desigualdade, ficava claro que, para o nosso autor, as únicas paixões naturais que se pode atribuir à natureza humana enquanto tal são a piedade natural e o amor de si. Claro, com a ressalva de que se trata de 
princípios e não propriamente de sentimentos experimentados efetivamente pelo homem natural que vive disperso no seio da natureza. Ocorre que, se acompanhamos todo o percurso do Emílio, sem nos restringirmos ao Livro IV ou, mais especificamente, à Profissão de fé do vigário saboiano, a consciência moral aparece, menos como um instinto ou um princípio presente desde sempre na natureza humana, e mais como um sentimento ou uma experiência que se constitui enquanto desdobramento das paixões primitivas ou originárias. Os sentimentos da consciência moral seriam como sentimentos sem objetos, pura interioridade e, por serem apresentados pelo autor como uma decorrência da natureza humana, daí derivam sua objetividade, isto é, aquilo que faz com que não se prestem apenas às variações das emoções, afetos e paixões experimentadas.

Entretanto, mesmo este aspecto da teoria da consciência, que nos permite vincular sentimentos como o amor da justiça, do bem ou da virtude, às paixões ditas naturais, leva-nos a uma complicação, já que, além dos sentimentos naturais, como seriam a compaixão e o chamado amor de si mesmo, o autor supõe também na formulação da concepção da consciência moral as idéias abstratas, como a do bem ou a da justiça. Kant percebeu esse engate na obra do filósofo genebrino e inspirou E. Cassirer a afirmar a consciência moral na obra de Rousseau como uma cidadã de dois mundos, habitando, pois, ao mesmo tempo natureza e mundo inteligível, participando, então, do empírico e do ideal ${ }^{11}$. Nossa tese consiste em afirmar que isto que aparenta ser uma duplicidade na obra de Rousseau é, entretanto, resultado da cumplicidade entre duas faculdades da alma humana, a consciência moral e a razão. Há aqui, implicada nesse acordo entre as duas faculdades, uma relação entre as idéias da razão e os sentimentos morais ${ }^{12}$, imbricação que não passou despercebida na leitura que fez Kant de Rousseau.

Princípio infalível do bem e do mal, e guia seguro da razão, a consciência moral protagoniza toda a experiência humana no que diz respeito às significações dos termos que importam concomitantemente ao conhecimento e à ação moral como, por exemplo, as significações dos termos bem, justiça, ordem ou perfeição. A metafísica do vigário saboiano, situada no Livro IV do Emílio, pode também ser considerada como uma exposição das tentativas empreendidas na história da filosofia concernentes à fundamentação da experiência moral. Daí, finalmente, seu recurso aos planos da ordem universal e da perfeição, assim como a afirmação dos três artigos de fé que se constituem como alicerces da vida moral. O que confere objetividade à consciência moral, para além das oscilações das paixões, encontramos nesse trajeto exposto claramente ao longo do Emílio, trajeto que vai das paixões primitivas a um mundo, por assim dizer, superior, mundo que nos é aberto pela consciência, e nesse sentido ideal e inteligível. Se a Profissão de fé não resume a teoria da consciência moral, ela constitui seu momento de maior gravidade.

O bem e a justiça pertencem ao mundo inteligível, permitindo-nos explicar a existência dos sentimentos morais inatos. A inteligibilidade das idéias morais decorre dessa cumplicidade entre razão e sentimento, as quais conferem à moralidade um padrão, possibilitando que diferentes indivíduos alcancem valores, idéias e princípios comuns. Ainda que não pudéssemos encontrar um 
ponto comum em que os interesses pudessem convergir, teríamos a capacidade de negociar, discutir, escolher e decidir a propósito das idéias, valores e princípios mais fundamentais para a história humana e para a realização das aspirações individuais. A concepção dos direitos naturais na obra de Rousseau decorre desse processo de criação, discussão e negociação, não perdendo seu caráter histórico, próprio à modernidade instaurada por Hobbes. Além dessa caracterização dos direitos mais fundamentais criados pelo homem, nosso autor acrescenta em sua obra Emílio, com a teoria da consciência, uma reflexão acerca da possibilidade de inteligibilidade das idéias gerais ou universais.

Em decorrência do pensamento de Rousseau, com efeito, o estatuto que se pode conferir aos direitos do homem nunca é o de um direito natural preexistente à associação civil. Entretanto, concepções como as dos direitos humanos, considerados fundamentais para a paz, a liberdade, a justiça e a dignidade humana, não ficam sem firmes alicerces na história do pensamento jurídico. De acordo com a tendência geral da filosofia moderna, podemos explicar a inteligibilidade das concepções dos direitos do homem a partir de uma investigação da natureza humana. Encontramos na obra de Rousseau esta peculiaridade, comum à teoria da consciência e à teoria da vontade geral, que consiste em fazer convergir mundo natural e mundo inteligível. Ora, assim como em sua perspectiva, a noção do natural incorpora a do inteligível, possibilitando que se fundamente uma parte da obra humana como algo inerentemente bom, belo ou justo, à concepção dos direitos do homem poderíamos também integrar ao mesmo tempo aspecto histórico e inteligibilidade natural. Colocamo-nos, portanto, diante de um direito fundamental resultante da obra humana, elaboração histórica do direito, que nem por isso faz dele arbitrário, frágil ou vulnerável.

Esse modo de fundamentar as idéias morais e os princípios jurídicos pode ser, ainda, uma boa estratégia para se fazer contrapeso à frieza das idéias gerais ou abstratas. Por um lado, temos uma razão calculadora, a qual Rousseau prefere chamar de raciocínio $^{13} \mathrm{e}$, por outro, uma razão esclarecida pelos sentimentos da consciência moral. A primeira desconhece os princípios morais, dirigindo-se mais à realização dos interesses particulares, na dependência das variações dos gostos e preferências pessoais. A segunda é aquela que, mantendo-se em sintonia com os princípios da consciência, dirige-nos para o bem comum. A racionalidade adequada à discussão sobre o princípio da vontade geral atrela-se a uma razão desse tipo, assim como a elaboração, o reconhecimento e o respeito dos direitos humanos. Todavia, a razão por si mesma é fria; nem é ela a faculdade dos princípios morais. Daí a afirmação do primado do sentimento sobre a razão na obra do filósofo genebrino e que aparece, de modo mais explícito, no Emílio. A razão é insuficiente para dirigir as ações humanas em direção ao bem comum.

A ênfase na limitação da razão não implica sobremaneira que, na perspectiva desse autor, os princípios da vontade geral ou as concepções dos direitos do homem possam ser considerados irracionais. A consciência moral reside, pois, também no mundo inteligível. Não há na obra de Rousseau uma defesa da irracionalidade. Voltar-se para os princípios ou sentimentos morais, afirmando o primado da consciência sobre a razão, longe de constituir uma atitude de negação da 
razão, implica também na aceitação de que, não obstante sua condição de criação humana, todas as idéias e princípios morais possuem uma ancoragem na natureza. Essa pressuposição permite afirmar a possibilidade de compartilharmos princípios e idéias, como fazemos quando fixamos conteúdos para a vontade geral ou quando conferimos significações para as concepções mais abstratas da razão, tal como a concepção dos direitos humanos. Assim, a teoria da consciência de Rousseau, na medida em que supõe a convivência entre natureza e mundo inteligível, permite-nos pensar a inteligibilidade das idéias morais e, mais especificamente, a possibilidade de reconhecimento universal dos direitos humanos.

No Discurso sobre a desigualdade, Rousseau afirma existir dependência entre as idéias gerais e o fato da linguagem: "as idéias gerais só podem entrar no espírito com a ajuda das palavras, e o entendimento só as capta através das proposições" ${ }^{14}$. Não precisaríamos nos perguntar pela eficácia da Declaração dos direitos humanos se considerássemos que a mera menção da palavra direitos humanos fosse suficiente para gerar no espírito a idéia dos direitos do homem. É claro que não se trata de afirmar que, para o autor, as palavras são condições suficientes para a formação das idéias. Lembremos que o contexto de sua exposição do problema da linguagem é também o da discussão acerca da diferença específica entre o homem e os outros animais. Rousseau pretende defender, com essas considerações, que há uma diferença qualitativa na natureza humana atrelada à linguagem, condição para a formação no espírito das idéias gerais ou abstratas, sem as quais nem haveria no homem perfectibilidade. A perfectibilidade é uma espécie de faculdade virtual que leva a humanidade ao aperfeiçoamento, que serve como princípio de modificação da natureza humana e aguarda, para se desenvolver e entrar em ação, as condições apropriadas provindas do ambiente natural e do conjunto da obra humana.

Nessa obra, particularmente no que diz respeito à linguagem e sua relação com a formação das idéias, tratava-se também de saber de que modo seres dispersos no seio da natureza poderiam formar no espírito idéias gerais ou abstratas. "Toda idéia geral é puramente intelectual." ${ }^{15} \mathrm{O}$ homem no puro estado de natureza, segundo a exposição de Rousseau, ainda não possui um aparato intelectual sofisticado. Não estão inscritas na natureza humana as idéias morais. O percurso necessário para que a humanidade pudesse aprender a elaborar idéias mais sofisticadas, mais complexas, como a própria idéia do direito ou da justiça, foi longo e pressupõe a linguagem. Nosso autor parece defender também a tese de que há uma ruptura entre as idéias resultantes de combinações ou comparações entre sensações e as idéias puramente intelectuais. Mas será que há, efetivamente, para ele, um abismo entre esses dois planos, o sensível e o intelectual? Não podemos decidir aqui acerca de uma questão tão controversa como esta, dadas as sutilezas de sua argumentação. Podemos notar, todavia, que, no Emílio, Rousseau distingue dois tipos de objetos, os objetos sensíveis e os intelectuais ${ }^{16}$, e dois tipos de razão, a razão sensitiva e a razão intelectual ${ }^{17}$.

É importante ressaltar a imbricação existente, para o autor, entre linguagem e racionalidade. Sem as palavras e as proposições não existem idéias gerais. Poderíamos ir mais longe seguindo as vias 
traçadas em sua obra e afirmar que, no fato da linguagem, integram-se o sensível e o intelectual. É com auxílio da linguagem que se pode estender a razão para além dos limites do sensível, lançando-a no terreno dos objetos puramente intelectuais. Esse fato, isto é, o ato da linguagem que nos permite passar de um plano a outro, seria o degrau de que o homem necessita para conferir significações às idéias gerais ou universais, para além do uso da chamada razão sensitiva. A linguagem articula-se, então, de modo a permitir que a razão se exerça sobre objetos intelectuais, palavras ou significações gerais ou universais.

Podemos tomar como referência as sugestões de M. Dascal concernentes ao tratamento da linguagem em sua relação com as paixões. Perspectiva que é, aliás, adotada por Bento Prado Jr. em seus estudos da filosofia de Rousseau, mais particularmente, em seus textos dedicados ao Ensaio sobre a origem das línguas. O exame do aspecto retórico da linguagem, aspecto tratado nessa obra, segundo Dascal, embora não deva ser deixado de lado, não dá conta das questões concernentes à função cognitiva da linguagem, exposta no Discurso sobre a desigualdade. A ênfase na função expressiva da linguagem, pela qual se ressalta sua origem passional, não nos permitiria, de seu ponto de vista, compreender o modo como as palavras são necessárias para o pensamento. Dito de outro modo: da retórica não seria possível extrairmos uma lógica ${ }^{18}$. Apesar disso, notamos que a própria afirmação segundo a qual só pensamos com as palavras, todavia, não prescinde de considerações prévias acerca do aspecto expressivo da linguagem.

Se a busca pela origem das línguas, tal como havia sido empreendida no Ensaio, pode ser aqui deixada de lado, o mesmo não podemos dizer acerca desse vínculo entre as faculdades racionais e as paixões. Mas, então, teríamos que estender o problema da relação entre linguagem e pensamento para um exame das imbricações entre a fabricação de idéias pela razão e os sentimentos ou paixões? Do ponto de vista de Rousseau, entre o uso das palavras e a formação das idéias, como vimos, ocorre uma espécie de cooperação; há aqui uma relação de dependência, já que o espírito não forma as idéias gerais sem o auxílio de palavras e proposições. É próprio ao homem, segundo Rousseau, como aquilo mesmo que o distingue dos outros seres da natureza, conferir uma significação às idéias gerais, como podemos notar, tanto no Discurso sobre a desigualdade como no Emílio. Esse ato de linguagem, pelo qual conferimos significações às idéias gerais ou universais, pode ser melhor compreendido com o auxílio da investigação dos aspectos originários da linguagem. Acompanhamos, então, essa investigação na obra do autor, não no intuito de buscar uma história factual das línguas, mas de distinguir os princípios que nos permitem explicar a inteligibilidade das idéias universais. $\mathrm{O}$ fato da linguagem ajuda-nos na formação das idéias gerais, sendo até mesmo para isso determinante. Mas não é desprezível a importância de se considerar, como faz Rousseau, estes dois aspectos - a fratura entre os objetos sensíveis e os objetos intelectuais, por um lado, e, por outro, a reciprocidade entre a razão propriamente dita e as paixões - para explicitarmos as condições de possibilidade da formação das idéias gerais que envolvem o fato da linguagem.

Não consideramos, portanto, haver uma grande discrepância entre esses dois tipos de leitura 
da obra de Rousseau, conforme se enfatize os aspectos cognitivos do problema da linguagem ou a função expressiva desta. Como vimos, razão e sentimento articulam-se no pensamento do autor, não sendo espantoso que a questão da linguagem seja colocada, ora em seus aspectos cognitivos, dada a função da linguagem na formação das idéias, ora em seus aspectos retóricos, decorrentes da influência dos sentimentos morais. No plano da linguagem, assim como no âmbito dos desejos e paixões, cada ato ou movimento do espírito supõe a existência de um aparato intelectual bastante sofisticado. Entretanto, como notamos no Discurso sobre a desigualdade, reciprocamente, para o autor, as capacidades humanas mais sofisticadas, intelectuais, dependem também para se desenvolver, isto é, para se tornarem efetivamente ativas, da sofisticação da linguagem ou, dito de outro modo, da abstração das palavras.

O problema da inteligibilidade e da universalidade dos direitos humanos envolve esses domínios que não podem ser inteiramente separados: o da linguagem, o da razão e o das paixões. A concepção dos direitos humanos apresenta esta peculiaridade: ela tem uma base na natureza e, não obstante, precisa ser construída historicamente, permanecendo num estado dinâmico de constante elaboração no espírito. Essa idéia moral envolve uma abstração intelectual, mas não deixa, contudo, de responder aos anseios comuns da humanidade. Nesse sentido, podemos compartilhar da crença de que o reconhecimento dos direitos humanos é, em parte, uma questão moral, pertencente ao âmbito da consciência individual. Qualquer ser racional, humano, dotado de razão e sensibilidade, é capaz, dadas as devidas circunstâncias, de perceber a importância de se apelar para tal idéia na tentativa de frear as paixões violentas, as injustiças e o combate travado entre indivíduos ou grupos com culturas diversas e interesses divergentes. Qualquer ser racional é, pois, capaz de reconhecer que a concepção dos direitos humanos responde às aspirações individuais, envolvendo respeito à diversidade e à dignidade humana.

Não obstante, reconhecer e conceber tal concepção não implica imediatamente em sua aceitação enquanto princípio de conduta. Resta ainda a questão de saber em que condições, além de inteligível para todos os seres que são ao mesmo tempo racionais e sensíveis, a idéia dos direitos humanos envolve também respeito. A extensão de tal idéia para todos os povos e nações, sua universalidade, depende em parte dos mecanismos capazes de fazer agir as capacidades intelectuais - no âmbito da razão, da consciência e da linguagem - mas também requer uma estratégia de aceitação do diferente e, portanto, do estímulo à tolerância. 


\section{Referências}

BARRET-KRIEGEL, B. Le Droits de l'Homme et le Droit Naturel. Paris : P.U.F., 1989.

BOBBIO, N. A Era dos Direitos. Trad. C. N. Coutinho. Rio de Janeiro: Campus, 1992.

BLOCH, E. Droit naturel et dignité humaine. Trad. D. Authier ; J. Lacoste. Paris : Payot, 2002.

CASSIRER, E. La Philosophie des Lumières. Trad. P. Quillet. Paris : Fayard, 1966.

CASSIRER, E. L'unité dans l'oeuvre de Rousseau. In : Pensée de Rousseau. Ed. G. Genette ; T. Todorov. p. 41-65. Paris : Seuil, 1984. (Artigo publicado também no Bulletin de la Société Française de Philosophie, XXXII, 1932).

COBBAN, A. Rousseau and the modern state. $2^{\mathrm{a}}$. ed. London: s George Allen \& Unwin, 1964.

DASCAL, M. Linguagem e pensamento segundo Rousseau. Manuscrito. V. III, n. 2, abr. 1980.

GURVITCH, G. L'Idée du droit social: notion et système du droit social. Histoire doctrinale depuis le XVIIe. Siècle jusqu'à la fin du XIXe. Siècle. Paris : Recueil Sirey, 1932.

RIALS, S. La Déclaration des droits de l'homme et du citoyen. Paris : Hachette, 1988.

ROUSSEAU, J.-J. Oeuvres complètes de Jean-Jacques Rousseau. Paris : Gallimard, 1964-1995. 5

v. (Coleção Bibliothèque de la Pléiade).

TALMON, J. L. Los Origines de la democracia totalitária. México: Aguillar, 1956. 


\section{Notas}

${ }^{1} \mathrm{O}$ debate sobre o estatuto dos direitos do homem remonta à época mesmo de elaboração da Declaração dos direitos do homem e do cidadão, em 1789. Podemos citar as críticas de E. Burke, que se indagava acerca da universalidade dos direitos do homem proclamados pelos franceses no período revolucionário. Para um exame das discussões e interpretações que envolvem as concepções dos direitos do homem, ver, de Stéphane Rials, La Déclaration des droits de l'homme et du citoyen (Paris : Hachette, 1988), de Blandine Barret-Kriegel, Les Droits de l'homme et le droit naturel (Paris : PUF, 1989) e, de E. Bloch, Droit naturel et dignité humaine (Paris : Payot, 2002). A elaboração do presente artigo foi iniciada por ocasião da palestra que apresentei em abril de 2009 no I Colóquio Unifesp de Filosofia Política e do Direito, a convite do Prof. Fernando Dias Andrade, a quem devo meus mais sinceros agradecimentos.

${ }^{2}$ As concepções do direito natural e da lei natural na obra de Rousseau aparecem de modo bastante complexo. Há um debate sobre esse tema na história das interpretações de sua filosofia. Como não é nossa finalidade aqui fazer uma apresentação dessas interpretações, remetemos aos comentários de R. Dérathé, em J.-J. Rousseau et la science politique de son temps (Paris: PUF, 1950), obra de referência que, aliás, acaba de ser publicada em português (São Paulo: Humanitas; Barcarolla, 2009).

${ }^{3}$ Cf. N. Bobbio, em A Era dos direitos. Trad. C. N. Coutinho. Rio de Janeiro: Campus, 1992.

${ }^{4}$ Ver nosso estudo $A$ Contradição entre o homem e o cidadão: consciência e política segundo J.-J. Rousseau (São Paulo: Humanitas, 2001), mais particularmente capítulo 4 sobre a vontade geral.

${ }^{5}$ Há vários autores implicados nessas discussão: C. E. Vaughan, R. Dérathé, B. Constant, sem remontarmos à tradição de intérpretes e autores que remonta ao período da Revolução Francesa. Recomendamos, mais particularmente, para uma apresentação geral da questão, o livro de A. Cobban, Rousseau and the modern state ( $2^{\mathrm{a}}$. ed.. London: George Allen \& Unwin, 1964).

${ }^{6}$ Cf. L'Idée du droit social: notion et système du droit social. Histoire doctrinale depuis le XVIIe. Siècle jusqu'à la fin du XIXe. Siècle. (Paris : Recueil Sirey, 1932).

${ }^{7}$ A comparação é do próprio Rousseau, que também emprega a expressão "vontade de todos", definindo-a como "soma das vontades particulares" ao passo que a vontade geral é apresentada como "soma das diferenças" (Contrato social, Livro II, Capítulo 3).

${ }^{8}$ Esses eram os termos de J. L. Talmon, em Los Origines de la democracia totalitária (México: Aguillar, 1956).

${ }^{9}$ Trata-se da aparição do termo vontade geral no verbete Economia política, na Enciclopédia. Cf. Oeuvres complètes de J.-J. Rousseau. Paris : Gallimard, 1964. v. 3. p. 245 (Bibliothèque de la Pléiade).

${ }^{10}$ Trata-se do Capítulo 2 do Livro I do Manuscrito de Genebra. Cf. Oeuvres complètes, op. cit. p. 286.

${ }^{11}$ Cf. seu livro Filosofia da Ilustração (La Philosophie des Lumières. Trad. P. Quillet. Paris : Fayard, 1966), assim como o artigo «L'unité dans l'oeuvre de Rousseau », publicado na coletânea Pensée de Rousseau. (Paris : Seuil, 1984). ${ }^{12}$ Há na obra de Rousseau considerações importantes acerca da complexa relação entre sentimentos e idéias. Privilegiamos em nossos estudos o primado dos sentimentos morais. Entretanto, não se pode ignorar que, em alguns aspectos, existe dependência dos sentimentos da consciência moral em relação às idéias abstratas ou gerais. Não é possível, por exemplo, amar ao bem sem antes se ter formado no espírito a idéia do bem.

${ }^{13}$ Raisonnement, raciocínio, que se caracteriza como arte de comparar, enquanto a razão é a faculdade de ordenar todas as faculdades da alma. Cf. a Segunda das Cartas Morais (Oeuvres complètes, op. cit., v. 4, p. 1090).

${ }^{14}$ Cf. Primeira Parte do Discurso sobre a desigualdade (Oeuvres completes, op. cit., v. 3. p. 149).

${ }^{15}$ Ibid., p. 150.

${ }^{16}$ Emílio, Livro III. (Oeuvres complètes, op. cit., v. 4. p. 430).

${ }^{17}$ Emílio, Livro II (ibid., p. 417).

${ }^{18}$ Cf. o artigo de M. Dascal, "Linguagem e pensamento segundo Rousseau”, publicado na revista Manuscrito. V. III, n. 2, abr. 1980. 